\title{
MODELING AND OPTIMIZING A VACUUM GAS OIL HYDROCRACKING PLANT USING AN ARTIFICIAL NEURAL NETWORK
}

\author{
Sepehr Sadighi ${ }^{1 *}$, Seyed Reza Seif Mohaddecy ${ }^{1}$, Ali Abbasi ${ }^{1}$ \\ ${ }^{1}$ Catalysis Research Division (CRD), Research Institute of Petroleum Industry (RIPI), West side of \\ Azadi Complex, 1485733111, Tehran, Iran
}

(Received: August 2017 / Revised: September 2017 / Accepted: January 2018)

\begin{abstract}
In this research, based on actual data gathered from an industrial scale vacuum gas oil (VGO) hydrocracker and artificial neural network (ANN) method, a model is proposed to simulate yields of products including light gases, liquefied petroleum gas (LPG), light naphtha, heavy naphtha, kerosene, diesel and unconverted oil (off-test). The input layer of the ANN model consists of the catalyst, feed and recycle flow rates, and bed temperatures, while the output neurons are yields of those products. The results showed that the AAD\% (average absolute deviation) of the developed ANN model for training, testing, and validating data are $0.445 \%$, $1.131 \%$ and $0.755 \%$, respectively. Then, by considering all operational constraints, the results confirmed that the decision variables (i.e., recycle rate and bed temperatures) generated by the optimization approach can enhance the gross profit of the hydrocracking process to more than $\$ 0.81$ million annually, which is significant for the economy of the target refinery.
\end{abstract}

Keywords: Artificial neural network; Hydrocracking; Modeling; Optimization; Vacuum gas oil

\section{INTRODUCTION}

Hydrocracking is a catalytic process for converting heavy oil materials, such as vacuum gas oil (VGO), into more valuable products with lower boiling points, such as gasoline, kerosene, and diesel (Becker et al., 2016). This process is the most suitable source for the production of diesel fuel with low sulfur and aromatics and for jet fuel with a high smoke point. The presence of hydrogen, which improves the combustion properties in hydrocracking products, enables this technology to provide the features needed for present and future fuels. Due to the important role of converting heavy oil cuts into light desirable products, the hydrocracking process has always been of interest to craftsmen and researchers for the production of high-quality middle distillates (Boosari et al., 2017). Reactions that occur in the hydrocracking reactor include breaking down (cracking) and converting the high molecular weight compounds into lower molecular weight ones and hydrogenating olefins, aromatics, sulfur, nitrogen, and some oxygen compounds. The hydrocracking reactions are a little endothermic, while the hydrotreating ones are exothermic; as a result, the general nature of the hydrocracking process is exothermic.

To handle sensitivity analyses, optimization, designs, and process control, a model is needed (Sadighi, 2016). However, in the hydrocracking process, as with other refining processes, the feed complexity and the presence of many hydrocarbons in products make it difficult to identify and introduce all the factors needed to develop a fundamental model (Sadighi et al., 2010). To

\footnotetext{
*Corresponding author's email: sadighis@ripi.ir, Tel: +98-021-4825-5011, Fax: +98-021-4473-9709 Permalink/DOI: https://doi.org/10.14716/ijtech.v9i1.44
} 
solve this problem, several articles presented kinetic models of this process using lumping methodology, in which the ingredients were classified in a certain range of boiling points based on density and molecular weight (Balasubramanian \& Pushpavanam, 2008; Esmaeel et al., 2016; Elizalde et al., 2016; Calderon \& Ancheyta, 2016; Faraji et al., 2017). The main problems preventing broader applications of this methodology are the complexity of model structure, the precise analysis of products, and the prolonged computational time.

Artificial neural networks (ANNs) represent the massive parallel interconnections of a simple neuron that functions as a collection system, and they are designed in an attempt to mimic the human brain and to emulate human performance; that is, to function intelligently (Kusumoputro et al., 2016). ANNs have gained immense popularity due to their ability to learn from past examples and to derive explicit relationships that are difficult to formulate using traditional methods of computing (Chandwani et al., 2015). This technique is based on information compiled from the process, and without any need for identifying the physical and chemical characteristics of the feed and products, the desired outputs, such as yield or conversion, can be simulated (Sadighi et al., 2013). In this respect, many researchers have modeled or optimized the VGO hydrocracking process; however, most of them reported increases in the yield of specific products (middle distillate or naphtha), regardless of the profit, process limitations, and catalyst life (Bhutani et al., 2006; Bahmani et al., 2010; Alhajree et al., 2011; Vasseghian \& Ahmadi, 2014). Moreover, this method was applicable for simulating the behavior of intricate relationship processes, such as the catalytic-dielectric barrier discharge plasma system (Istadi \& Amin, 2006; Istadi \& Amin, 2007).

In this research, based on data collected from a VGO hydrocracking unit in an Iranian refinery, the yield of the process to produce light gases, LPG (liquefied petroleum gas), light and heavy naphtha, kerosene, diesel, and unconverted oil has been modeled using the ANN modeling approach. Then, by applying the proposed model, the gross profit of this unit has been optimized on the basis of the added value function of products, while considering the operational limitations of the process.

\section{PROCESS DESCRIPTION}

In the target hydrocracking process, the VGO feed (see Table 1) obtained from the vacuum distillation tower is mixed with unconverted oil (off-test) and then is mixed with hydrogen.

Table 1 Specifications of the fresh VGO in the target process

\begin{tabular}{lrc}
\hline \multicolumn{1}{c}{ Variable } & \multicolumn{1}{c}{ Unit } & Value \\
\hline Fresh feed flow rate & $\mathrm{m}^{3} / \mathrm{h}$ & 163.7 \\
Density & $\mathrm{kg} / \mathrm{m}^{3}$ & 911 \\
Total Sulfur & $\mathrm{wt} \%$ & 1.4 \\
ASTM Distillation, D1160 & & \\
$\quad$ IBP & ${ }^{\circ} \mathrm{C}$ & 333 \\
$10 \%$ & ${ }^{\circ} \mathrm{C}$ & 389 \\
$30 \%$ & ${ }^{\circ} \mathrm{C}$ & 414 \\
$50 \%$ & ${ }^{\circ} \mathrm{C}$ & 434 \\
$70 \%$ & ${ }^{\circ} \mathrm{C}$ & 453 \\
$90 \%$ & ${ }^{\circ} \mathrm{C}$ & 481 \\
FBP & ${ }^{\circ} \mathrm{C}$ & 500 \\
\hline
\end{tabular}

This flow is passed through heat exchangers and heaters (Figure 1), and it is introduced to three parallel reactors, with each of them having four catalytic fixed beds. They contain $15 \%, 25 \%$, $30 \%$, and $30 \%$ of the total catalyst weight percentage, respectively. 


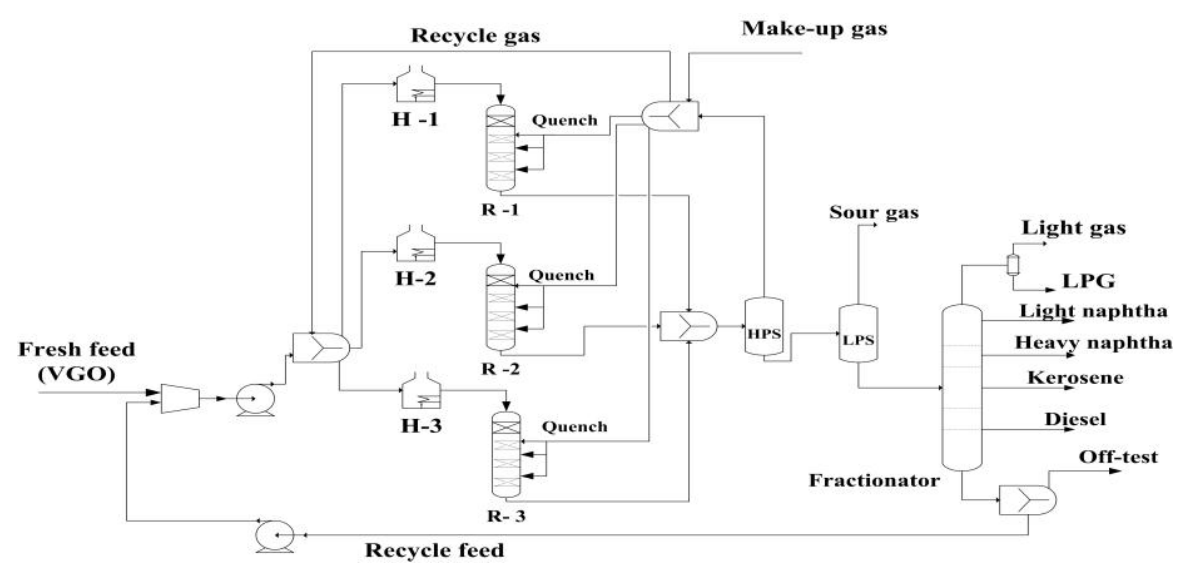

Figure 1 Block flow diagram of the target VGO hydrocracking plant

In the first bed, hydrotreating reactions are carried out to remove sulfur, nitrogen, and metal compounds. The second, third, and fourth catalytic beds often perform the hydrocracking reactions. The specifications of the hydrocracking catalyst are presented in Table 2.

Table 2 Specifications of the VGO hydrocracking catalyst loaded in the target plant

\begin{tabular}{lc}
\hline Catalyst type & Nickel-Tungsten \\
Catalyst shape & Trilobe \\
Nominal size, $\mathrm{mm}$ & 1.3 \\
Nickel oxide content, wt $\%$ & 6 \\
Tungsten oxide content, wt $\%$ & 26.5 \\
Pore volume, $\mathrm{cm}^{3} / \mathrm{g}$ & 0.5 \\
BET surface area, $\mathrm{cm}^{3} / \mathrm{g}$ & 225 \\
\hline
\end{tabular}

Along the hydrocracking reactor, quenching systems are provided for the purpose of controlling exothermic reactions (hydrotreating and hydrogenation). This facility injects hydrogen into the output stream, leaving the first, second, and third beds to reduce its temperature and therefore preserving the catalyst from excessive coke formation. Furthermore, at the top of the reactor, ceramic balls are used to distribute the feed and to prevent physical impurities from entering the reactor. The product, after passing through heat exchangers and air coolers, enters the highpressure separator (HPS). The hydrogen gas leaving the HPS with the purity of $86.3 \mathrm{~mol} \%$ is mixed with make-up hydrogen (purity of $96.5 \mathrm{~mol} \%$ ), and then its major part is added to the feed of the reactor. The other fraction of this stream is injected between the catalytic beds to control the reaction temperature.

The HPS effluent enters the low-pressure separator (LPS) and is separated into two streams: sour gas and a liquid product. The former enters the desulfurization unit, and the latter is introduced to the debutanizer tower. The liquid product leaving this tower enters the main fractionation column to obtain the hydrocracking products (i.e., light gas, LPG, light and heavy naphtha, kerosene, and diesel).

\section{METHODS}

\subsection{Modeling Method}

The success in modeling and achieving high precision in the ANN method is strongly dependent on the correct selection of process variables (input neurons) and also on the number of neurons in the hidden layers. Consequently, in this research, an attempt was made to select 
variables that strongly affect yields of hydrocracking products in the studied VGO hydrocracking unit. These variables are:

- Catalyst life (the cumulative volume of VGO feed passed through the total mass of the catalyst)

- Feed flow rate (Ff)

- Combined feed ratio (CFR)

- The temperature of catalytic beds $\left(\mathrm{T}_{1}, \mathrm{~T}_{2}, \mathrm{~T}_{3}\right.$, and $\left.\mathrm{T}_{4}\right)$

Since the specifications of feed (initial and final boiling points and sulfur and nitrogen content and density) changed less than 5\% during the period of study (557 days), these variables were ignored. Moreover, considering the approximate similarity of three trains of hydrocracking units in terms of the catalyst weight loaded in each reactor and feed flow rate, only one of them was modeled. To reduce the number of model coefficients and prevention from over fitting, a feed forward neural network was constructed with three neurons in the hidden layer.

In addition, the activation function used in the hidden nodes was the tangent sigmoid (Tansig) as follows:

$$
f(y)=\frac{e^{y}-e^{-y}}{e^{y}+e^{-y}}=\tan \operatorname{sig}(y)
$$

where $y$ is the sum of the weighted inputs to the neuron, and $f(y)$ is the output of the node. For creating the ANN model, the Newff syntax provided in MATLAB software (Mathworks, Inc.; 2013a) was applied. ANN is generally adjusted or trained so that a certain input is directed to the final specific target (Zuna et al., 2016). Hence, the training of ANN was performed by introducing a set of known inputs and outputs to learn the actual data trend by manipulating weights and biases (Sadighi \& Mohaddecy, 2013). Trainlm syntax in MATLAB was applied to train the network, which used the Levenberg-Marquardt algorithm. This procedure was continued until reaching the minimum mean squared error (MSE), and the ANN outputs (i.e., the yields simulated by the model) and targets (i.e., the actual values) were stable (Fachrurrazi \& Munirwansyah, 2017):

$$
M S E=\frac{1}{N} \sum_{j=1}^{N}\left(Y_{j, \text { actual }}-Y_{j, A N N \text { model }}\right)^{2}
$$

where $N$ is the number of data, $Y$ indicates the yield of the products. "actual" represents the measured yields, and the ANN model refers to the values simulated by ANN.

\subsection{Optimization Method}

To optimize the hydrocracking process, the gross profit function is maximized according to the following equation:

$$
\Delta \text { gross profit }=\sum_{j} m_{j} \times b_{j}-m_{f} \times b_{f}-\Delta \text { Expen }
$$

where the $m_{j}$ is the flow rate of strategic products, including light and heavy naphtha, kerosene, and diesel; $b_{j}$ is the price of product mass unit (Table 3 ); $b_{f}$ is the feed price, $m_{f}$ is the feed flow rate; and the $\Delta$ Expen function defines the energy, hydrogen, and operating costs. According to the results reported by Sadighi and Arshad (2013), $\Delta$ Expen is about $6.5 \%$ of the total increase in the gross profit, and therefore it is ignored to mitigate the complexity of the model. 
Table 3 Price of the VGO hydrocracking products (Asia-Pacific, 2016)

\begin{tabular}{lcc}
\hline \multicolumn{1}{c}{ Product } & Unit & Value \\
\hline Light naphtha & \$/MT & 464.7 \\
Heavy naphtha & \$/bbl & 464.11 \\
Kerosene & \$/bbl & 63.33 \\
Diesel (Gas oil) & \$/bbl & 62.35 \\
VGO & \$/MT & 404 \\
\hline
\end{tabular}

Additionally, by considering some process limitations (Equation 4), the above objective function was optimized by using the Fmincon syntax that was available in the MATLAB.

$$
\left\{\begin{array}{l}
m f=m f_{\text {actal }} \\
0.98 \times C F R_{\text {actual }} \leq C F R \leq 1.02 \times C F R_{\text {actual }} \\
\mid T b_{z}-T b_{z} \text { actual } \mid \leq 2{ }^{\circ} \mathrm{C}
\end{array}\right\}
$$

where, $z$ represents the first to fourth beds, and the actual symbol indicates the current conditions (before optimization).

The mentioned limitations were considered for the following reasons:

1) The flow rate of VGO could not be changed due to the restriction in the upstream process (vacuum distillation tower), and because of the lack of storage facilities,

2) The properties of middle distillates were subject to variation due to the excessive increase or decrease in the amount of recycle flow rate.

Sufficient hydrogen for the quenching system was not available; moreover, the formation of coke could be accelerated due to the rising temperature of beds.

\section{RESULTS AND DISCUSSION}

\subsection{Simulation of the Hydrocracking Process}

In the period of 557 days, 80 data points including catalyst life, VGO and recycle flow rates, temperatures of catalytic beds, and yield of products were collected from the target VGO hydrocracking unit. After performing the mass balance for each data point, only the ones with an error of less than 5\% were accepted. As a result, 69 valid points were obtained, which were divided into three categories: training, testing, and validating groups. They included 41,14 , and 14 data points $(60 \%, 20 \%$, and $20 \%$ of total data), respectively.

On the basis of reaching the minimum MSE up to 50,000 iterations, the results obtained for yields of products are presented in Table 4 . From this table, it can be concluded that the AAD\% of unforeseen data $(0.596 \%)$ used for the validation purpose was less than the AAD\% of testing data points $(1.131 \%)$, and it was also close to the AAD\% of trained data $(0.445 \%)$. To further investigate the accuracy of the model, the actual information on the yields of light gas, LPG, light and heavy naphtha, kerosene, diesel, and unconverted oil are presented in Figures 2 through 8, respectively. As seen, the ANN model has acceptable accuracy and therefore can be applied for the purpose of optimizing the target VGO hydrocracking process. The observed deviations may be due to random errors of measurement and some abnormal conditions in the process, such as the decreasing pressure of pumps and compressors, swinging in the quench flow rate, or reaching a flood condition in the separation towers. 
Table 4 AAD $\%$ of the ANN model in comparison to the actual data

\begin{tabular}{lccc}
\hline \multicolumn{1}{c}{ Product } & Training data (\%) & Testing data (\%) & Validating data (\%) \\
\hline Light gases & 0.091 & 0.189 & 0.096 \\
LPG & 0.197 & 0.644 & 0.204 \\
Light naphtha & 0.571 & 1.084 & 0.473 \\
Heavy naphtha & 0.477 & 0.644 & 0.428 \\
Kerosene & 0.334 & 0.335 & 0.423 \\
Diesel (Gas oil) & 0.386 & 1.272 & 0.972 \\
Residue & 1.062 & 3.750 & 1.580 \\
\hline \multicolumn{1}{c}{ Average } & 0.445 & 1.131 & 0.596 \\
\hline
\end{tabular}

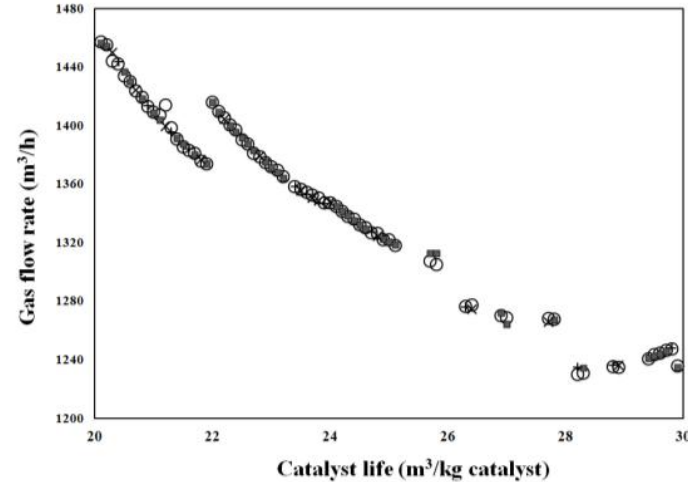

Figure 2 A comparison between simulated values with actual data for the gas yield

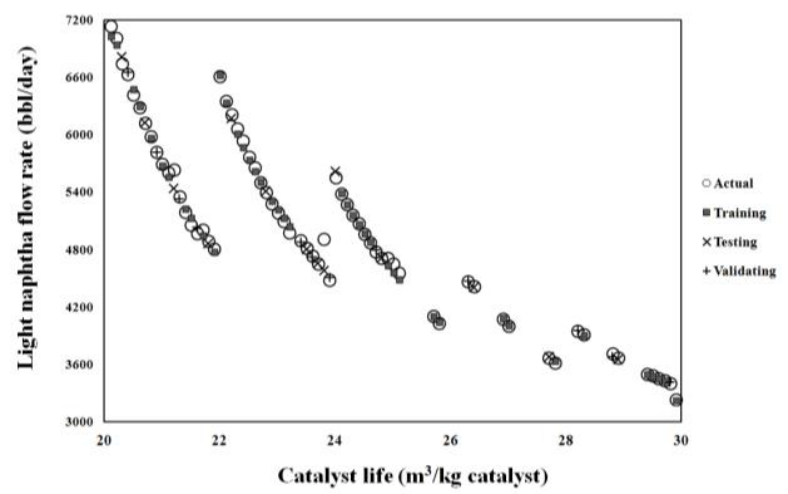

Figure 4 A comparison between simulated values with actual data for the light naphtha yield

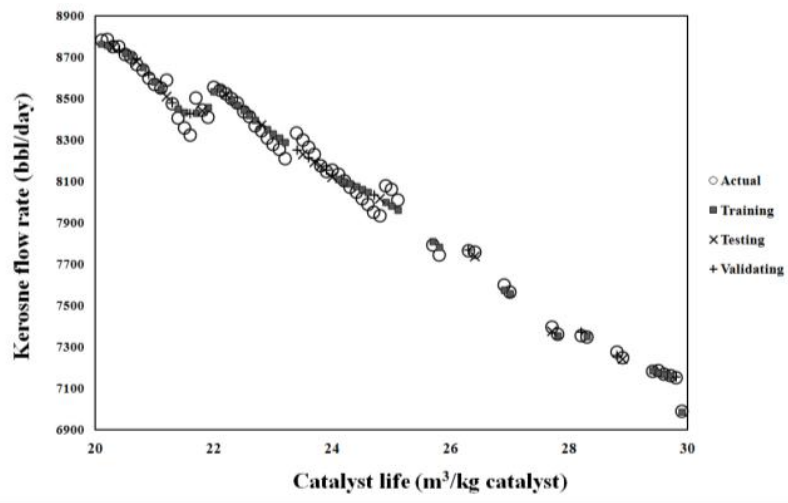

Figure 6 A comparison between simulated values with actual data for the kerosene yield

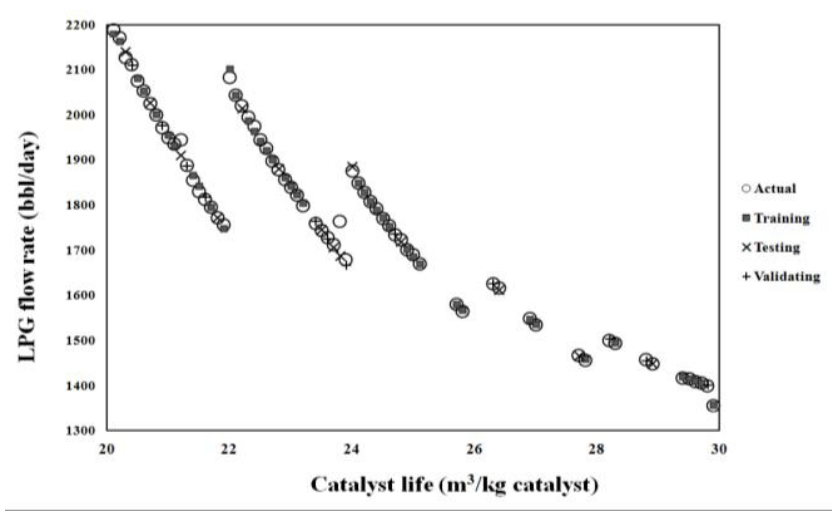

Figure 3 A comparison between simulated values with actual data for the LPG yield

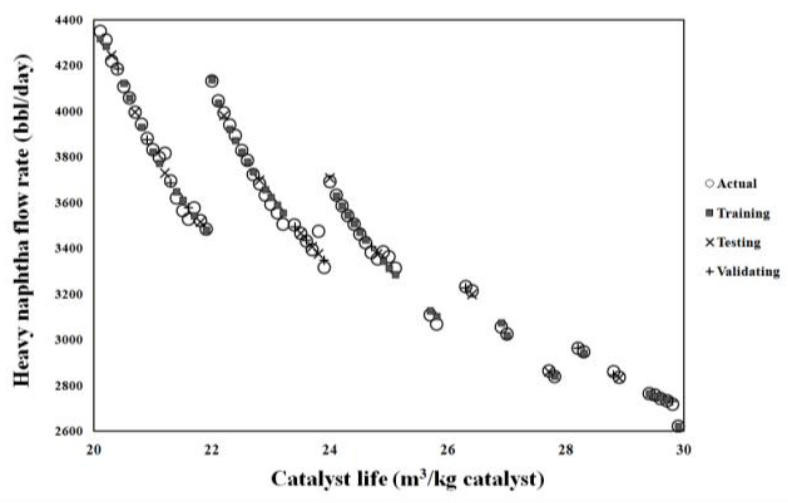

Figure 5 A comparison between simulated values with actual data for the heavy naphtha yield

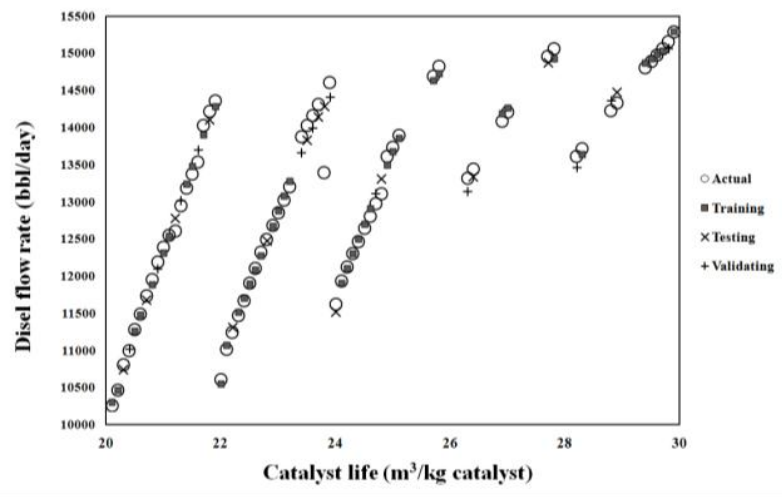

Figure 7 A comparison between simulated values with actual data for the diesel yield 


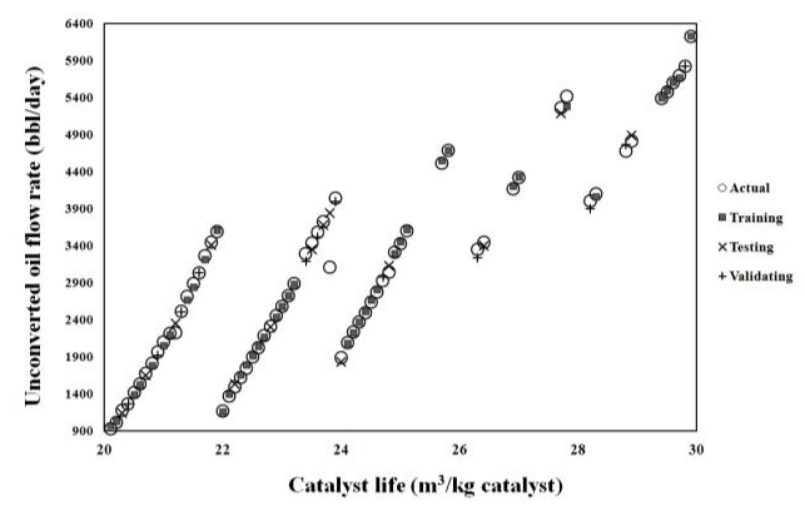

Figure 8 A comparison between simulated values with actual data for the off-test yield

\subsection{Optimization of the Hydrocracking Process}

The results related to the optimum values of the recycle flow rate compared to the current (actual) ones are presented in Figure 9. As shown, the actual value of this variable is the same as the optimum one; but for some data points, the value of the objective function (gross profit of the hydrocracking process) is enhanced by increasing this variable. It is confirmed that by increasing the recycle flow rate, the yield of the valuable products increases; thus, it has a positive impact on the profit of the VGO hydrocracking plant.

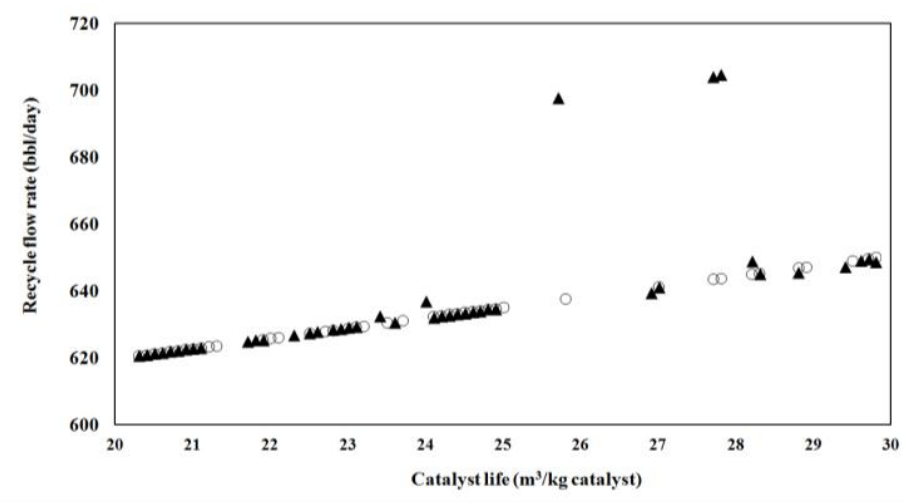

Figure 9 A comparison of the actual $(\circ)$ and optimized $(\boldsymbol{\Delta})$ values of recycle stream

The optimum values of input temperatures of the beds compared to the actual ones are shown in Figures 10 through 13. As seen, the current temperatures of the catalytic beds are slightly higher than the optimum value. Therefore, the temperature is the most effective variable in the VGO hydrocracking process, and it directly affects yields of products.

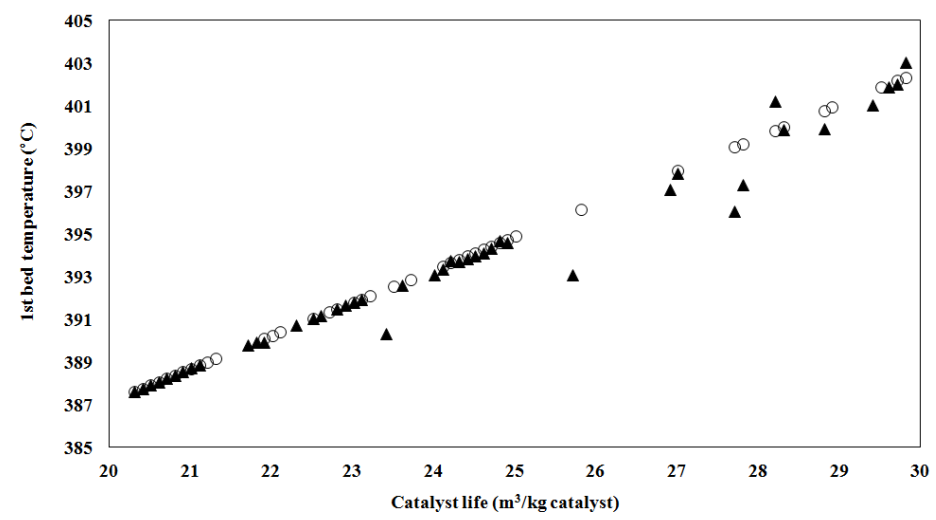

Figure 10 A comparison of the actual ( $($ ) and optimized $(\mathbf{A})$ temperatures of the first bed 


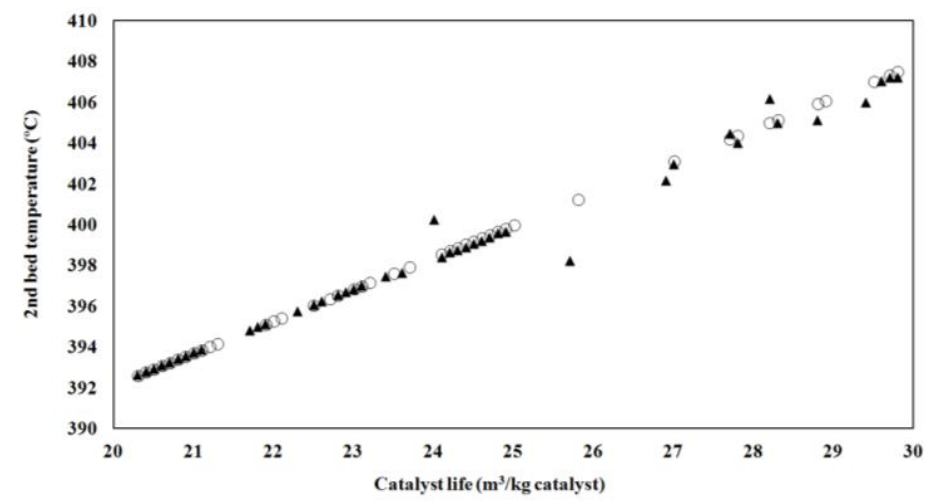

Figure 11 A comparison of the actual ( $($ ) and optimized $(\mathbf{\Delta})$ values of the second bed temperature

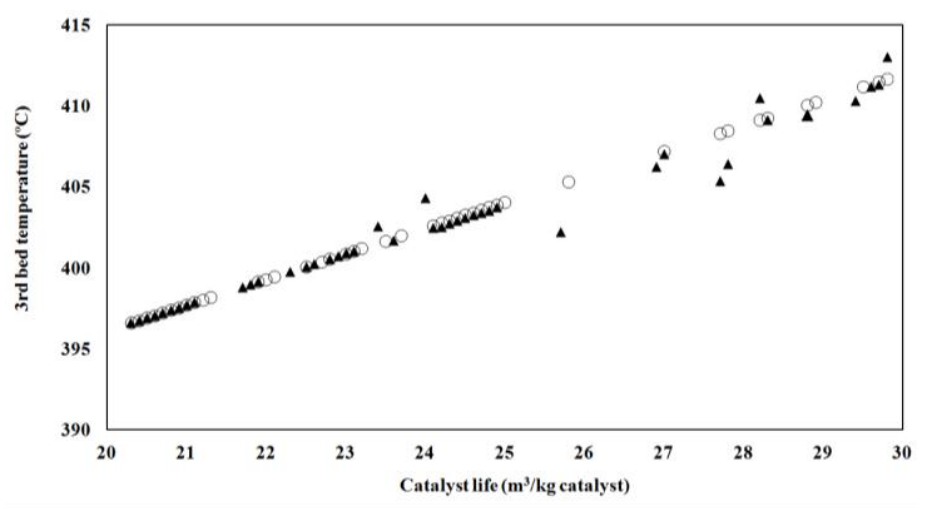

Figure 12 A comparison of the actual $(\circ)$ and optimized $(\boldsymbol{\Delta})$ values of the third bed temperature

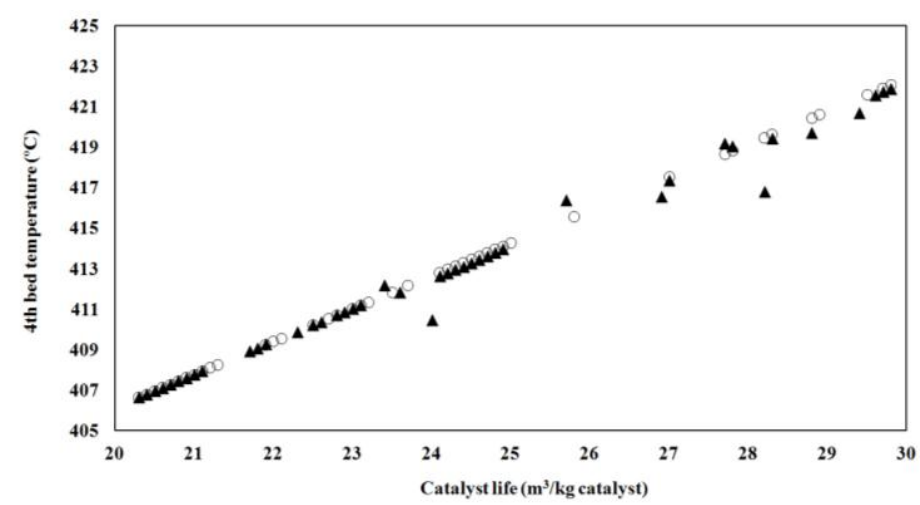

Figure 13 A comparison of the actual ( $($ ) and optimized $(\boldsymbol{\Delta})$ values of the fourth bed temperature

It is concluded that this variable should be carefully adjusted during the VGO hydrocracking process.

From Figure 10, it is concluded that the input temperature to the first catalytic bed should be reduced. Due to promoting hydrotreating reactions that are exothermic and reversible, the production of naphtha and middle distillate increases with reductions in the temperature (Sadighi et al., 2011). However, as seen in Figures 11 through 13, for the other beds, hydrotreating and hydrocracking reactions occur simultaneously. Since hydrocracking reactions are endothermic in nature and because they promote reactions by increasing temperature, the optimizer suggests the higher or lower temperatures for these beds in some cases. Meanwhile, it should be noted that the excessive increase of temperature leads to excess progress in 
hydrocracking reactions and therefore leads to the surplus production of light gas. This commodity is burned in the flare network due to its nontransferability from the refinery to the global pipeline, and therefore its production has environmental consequences. Furthermore, decreasing the temperature of catalytic beds reduces the coke deposition on the catalyst and increases its life. Thus, the optimized temperatures can positively affect the VGO hydrocracking process from both environmental and economical aspects.

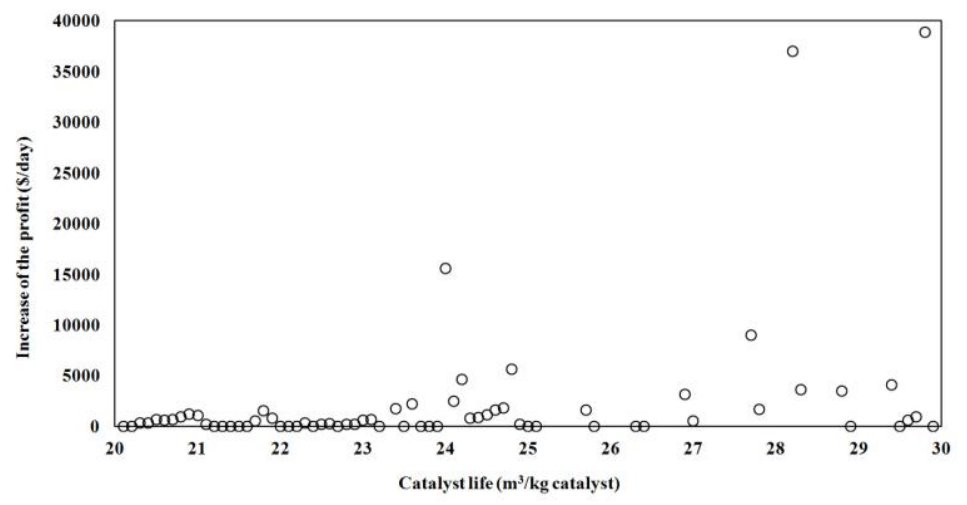

Figure 14 Increasing the profit of the target VGO hydrocracking plant after the optimization

Figure 14 shows the variations of the gross profit in the target hydrocracking process. As seen, by executing the optimization program and obeying the process limitations, the gross profit of the target plant increases about $\$ 4,000$ per day, which is equal to $\$ 810,000$ per year. Considering that the extra costs after optimization is less than $6.5 \%$ of the total increase in the gross profit, it can be expected that with the implementation of the proposed method, the profit of the process increases about $\$ 750,000$ per year.

Since the ANN model requires the actual information from the process, the required data should be collected in a three-month time interval, and then the operational conditions of next points can be optimized. Thus, by adding new points and continuing the implementation of the algorithm versus the catalyst lifetime, the precision of the model and subsequently the accuracy of optimization increases.

\section{CONCLUSION}

An industrial scale VGO hydrocracking unit was modeled using the ANN method. This model was designed based on a feed-forward neural network with seven neurons in the input layer and three neurons in the hidden layer. The input process variables were catalyst life, fresh and recycle feed flow rates, and the input temperature to each catalytic bed. For all VGO hydrocracking products (i.e., light gases, LPG, light and heavy naphtha, kerosene, diesel, and unconverted oil), the ANN model was trained, tested, and validated. The results showed that ANN could simulate yield of products for 69 operating points during 557 days with an AAD\% of $1.2 \%$.

To propose an application for the constructed ANN model, the gross profit function of the VGO hydrocracking plant was maximized by considering some limitations in the process. The results showed that within the permissible range for the manipulated variables (i.e., the recycle flow rate and bed temperatures), the average gross profit of the target unit could be increased to $\$ 810,000$ per year. Furthermore, due to the reduction in the temperature of hydrocracking beds after optimization, it was possible to reduce the coke formation on the catalyst surface, which subsequently would increase the cycle life of the catalyst. 


\section{REFERENCES}

Alhajree, I., Zahedi, G.R., Manan, Z.A., Mohammad Zadeh, S., 2011. Modeling and Optimization of an Industrial Hydrocracker Plan. Journal of Petroleum Science Engineering, Volume 78, pp. 627-636

Asia-Pacific/Persian Gulf MarketScan, 2016. Volume 35(49), pp. 1-16

Bahmani, M., Sharifi, K., Shirvani, M., 2010. Product Yields Prediction of Tehran Refinery Hydrocracking Unit. Iranian Journal of Chemical Engineering, Volume 7(4), pp. 50-60

Balasubramanian, P., Pushpavanam, S., 2008. Model Discrimination in Hydrocracking of Vacuum Gas Oil using Discrete Lumped Kinetics. Fuel, Volume 87, pp. 1660-1672

Becker, P.J., Celse, B., Guillaume, D., Costa, V., Bertier, L., Guillon, E., Pirngruber, G., 2016. A Continuous Lumping Model for Hydrocracking on a Zeolite Catalysts: Model Development and Parameter Identification. Fuel, Volume 164, pp. 73-82

Bhutani, N., Ray, A.K., Rangaiah, G.P., 2006. First-principles, Data-based, and Hybrid Modeling and Optimization of an Industrial Hydrocracking Unit. Industrial \& Engineering Chemistry Research, Volume 45, pp. 7807-7816

Boosari, S.H., Makouei, N., Stewart, P., 2017. Application of Bayesian Approach in the Parameter Estimation of Continuous Lumping Kinetic Model of Hydrocracking Process. Advances in Chemical Engineering and Science, Volume 7(3), pp. 257-269

Calderon, C.J., Ancheyta, J., 2016. Modeling of Slurry-phase Reactors for Hydrocracking of Heavy Oils. Energy \& Fuels, Volume 30, pp. 2525-2543

Chandwani, V., Agrawal, V., Nagar, R., Singh, S., 2015. Modeling Slump of Ready Mix Concrete Using Artificial Neural Network. International Journal of Technology, Volume 6(2), pp. 207-216

Elizalde, I., Trejo, F., Munoz, J.A.D., Torres, P., Ancheyta, J., 2016. Dynamic Modeling and Simulation of a Bench-scale Reactor for the Hydrocracking of Heavy Oil by using the Continuous Kinetic Lumping Approach. Reaction Kinetics, Mechanisms and Catalysis, Volume 118, pp. 299-311

Esmaeel, S.A., Gheni, S.A., Jarullah, T.A., 2016. 5-Lumps Kinetic Modeling, Simulation and Optimization for Hydrotreating of Atmospheric Crude Oil Residue. Applied Petrochemical Research, Volume 6(2), pp. 117-133

Fachrurrazi, Husin, S., Munirwansyah, Husaini, 2017. The Subcontractor Selection Practice using ANN-Multilayer. International Journal of Technology, Volume 8(4), pp. 761-772

Faraji, D., Sadighi, S., Mazaheri, D., 2017. Modeling and Evaluating Zeolite and Amorphous Based Catalysts in Vacuum Gas Oil Hydrocracking Process. International Journal of Chemical Reactor Engineering, Volume 16(1), pp. 1-14

Istadi, I., Amin, N.A.S., 2006. A Hybrid Artificial Neural Network-genetic Algorithm (ANNGA) Technique for Modeling and Optimization of Plasma Reactor. Industrial \& Engineering Chemical Research, Volume 45, pp. 6655-6664

Istadi, I., Amin, N.A.S., 2007. Catalytic-Dielectric Barrier Discharge Plasma Reactor for Methane and Carbon Dioxide Conversion. Bulletin of Chemical Reaction Engineering \& Catalysis, Volume 2, pp. 37-44

Kusumoputro, B., Sutarya, D., Faqih, A., 2016. Performance Analysis of an Automatic Green Pellet Nuclear Fuel Quality Classification using Modified Radial Basis Function Neural Networks. International Journal of Technology, Volume 7(4), pp. 709-719

Sadighi, S., 2016. Yield Control of a Pilot Scale Vacuum Gas Oil Hydrocracker using a SoftSensing Approach. Journal of Chemical Engineering of Japan, Volume 49(12), pp. 979986

Sadighi, S., Ahmad, A., Mohaddecy, S.R., 2010. 6-Lump Kinetic Model for a Commercial Vacuum Gas Oil Hydrocracker. International Journal of Chemical Reactor Engineering, Volume 7,pp. 1-25 
Sadighi, S., Arshad, A., 2013. An Optimisation Approach for Increasing the Profit of a Commercial VGO Hydrocracking process. Canadian Journal of Chemical Engineering, Volume 91, pp. 1077-1091

Sadighi, S., Arshad, A., Shirvani, M., 2011. Comparison of Lumping Approaches to Predict the Product Yields in a Dual Bed VGO Hydrocracker. International Journal of Chemical Reactor Engineering, Volume 9(A4), pp. 1-25

Sadighi, S., Mohaddecy, R.S., 2013. Predictive Modeling for Industrial Naphtha Reforming Plant Using Artificial Neural Network with Recurrent Layers. International Journal of Technology, Volume 4(2), pp. 102-111

Sadighi, S., Zahedi, S., Hayati, R., Bayat, M., 2013. Studying Catalyst Activity in an Isomerization Plant to Upgrade the Octane Number of Gasoline by using a Hybrid Artificial Neural Network Model. Energy Technology, Volume 1, pp. 743-750

Vasseghian, Y., Ahmadi, M., 2014. Artificial Intelligent Modeling and Optimizing of an Industrial Hydrocracker Plant. Journal of Chemical and Petroleum Engineering, Volume 48(2), pp. 125-137

Zuna, H.T., Hadiwardoyo, S.P., Rahadian, H., 2016. Developing a Model of Toll Road Service Quality Using an Artificial Neural Network Approach. International Journal of Technology, Volume 7(4), pp. 562-570 